\title{
Quantification of Furandiones in Ambient Aerosol
}

2

\section{$27 \quad$ Keywords}

\section{Abstract}

Ibrahim M. Al-Naiema, ${ }^{a}$ Hannah M. Roppo, ${ }^{a}$ and Elizabeth A. Stone ${ }^{\text {a, }}$

${ }^{a}$ Department of Chemistry, College of Liberal Arts and Sciences, The University of Iowa, Iowa City, IA, 52242, USA

* Corresponding author:

Elizabeth A. Stone, betsy-stone@uiowa.edu, Tel: 319-384-1863, Fax: 319-335-1270, Chemistry Building, Iowa City, IA 52242

Furandiones are products of the photooxidation of anthropogenic volatile organic compounds (VOC), like toluene, and contribute to secondary organic aerosol (SOA). Because few molecular tracers of anthropogenic SOA are used in to assess this source in ambient aerosol, developing a quantification method for furandiones holds a great importance. In this study, we developed a direct and highly sensitive gas chromatography-mass spectrometry method for the quantitative analysis of furandiones in fine particulate matter that is notably free from interference by structurally-related dicarboxylic acids. Our application of this method in Iowa City, IA provides the first ambient measurements of four furandiones: 2,5-furandione, 3-methyl-2,5-furandione, dihydro-2,5-furandione, and dihydro-3-methyl-2,5-furandione. Furandiones were detected in all collected samples with a daily average concentration of $9.1 \pm 3.8 \mathrm{ng} \mathrm{m}^{-3}$. The developed method allows for the accurate measurement of the furandiones concentrations in ambient aerosol, which will support future evaluation of these compounds as tracers for anthropogenic SOA and assessment of its potential health impacts.

Acid anhydride; fine particulate matter; anthropogenic VOC; secondary organic aerosol; method development; GCMS, succinic anhydride, methylsuccinic anyhydride, maleic anyhdride, citraconic anhydride

\section{Graphical abstract}




\section{Introduction}

Atmospheric particulate matter (PM) significantly and adversely affects human health (Dockery et al., 1993) and the Earth's climate (IPCC, 2007). Primary sources emit PM directly to the atmosphere, while secondary aerosol forms in the atmosphere. Secondary organic aerosol (SOA) forms by chemical reactions of volatile organic compounds (VOC) followed by condensation to the particle-phase. These reactions depend, in part, on the presence of available precursors and oxidants and the chemistry of existing particles (Kroll and Seinfeld, 2008).

Current knowledge of the precursors, mechanisms of formation, and properties of SOA is incomplete, leaving major gaps in understanding of exactly how, and to what extent, SOA affects air quality and climate (Foley et al., 2010).

The relative roles of natural and anthropogenic precursors to SOA remain highly uncertain. Some studies indicate dominance (>90\%) of biogenic precursors like isoprene (Hallquist et al., 2009), while others studies highlight the importance of anthropogenic VOC (>30\%), such as benzene and toluene (Henze et al., 2008; Volkamer et al., 2006). SOA products from aromatic VOC can help to constrain estimates of anthropogenic SOA contributions to ambient PM through an SOA tracer approach (Kleindienst et al., 2007). To date, anthropogenic SOA tracers are limited to one toluene oxidation product (2,3-dihydroxy-4-oxopentanoic acid) (Kleindienst et al., 2004; Offenberg et al., 2007) that has been used quantitatively and poly-carboxylic acids that have been used qualitatively (Fine et al., 2004). Other classes of compounds, such as furandiones, nitrophenols, and nitrobenzenes are products of benzene, toluene, xylenes, and other alkyl benzene SOA (Forstner et al., 1997; Hamilton et al., 2003; Kleindienst et al., 1999; Koehler et al., 2004; Volkamer et al., 2006) and may prove to be useful tracers. 
Furandiones, in particular, are among the most frequently identified products of aromatic

64 VOC oxidation in the presence of nitrogen oxides $\left(\mathrm{NO}_{\mathrm{x}}\right)$ (Bandow et al., 1985). They form through a ring opening mechanism, by which toluene or an alkyl benzene ring reacts with $\mathrm{OH}$ radical in the presence of $\mathrm{NO}_{\mathrm{x}}$. This process leads to the cleavage of benzene ring to form a cis-

67 butendial intermediate which undergoes cyclization leading to the formation of 2,5-furandione (Bandow et al., 1985; Forstner et al., 1997; Jang and Kamens, 2001). Forstner et al. (1997) have reported that 3-methyl-2,5-furandione, 2,5-furandione, and dihydro-2,5-furandione represent $58 \%$ of the total identified mass resulting from toluene, $66 \%$ from m-xylene, $35 \%$ from ethylbenzene, $34 \%$ from 1,2,3-trimethylbenzene, and 31\% from m-ethyltoluene photooxidation 72 in the presence of $\mathrm{NO}_{\mathrm{x}}$.

The potential for human exposures to furandiones in ambient air is significant, due to their adverse effects on the respiratory system. For example, acute inhalation of 2,5-furandione has been the source of irritation of the respiratory tract and chronic exposure has caused bronchitis, bronchial asthma, and irritation of the nose and eyes (CDC, 2015; EPA, 1992). 2,5-Furandione and dihydro-2,5-furandione, in particular, have been shown to produce these effects in human as ambient concentrations. well as in animal tests (EPA, 1992; NIH). Although less data is available on dihydro-2,5furandione, there is evidence that it irritates the eyes, skin, and respiratory tract $(\mathrm{NIH})$. Assessing the potential health effects of outdoor exposures to furandiones requires knowledge of their The water-sensitivity of these compounds presents analytical challenges in their measurement. Furandiones are anhydrides that undergo a ring opening reaction in the presence of water. Shown in Equation 1 is 2,5-furandione reacting with water to form (2Z)-2-butenedioic acid . Consequently, water must be avoided in sample preparation and analysis.

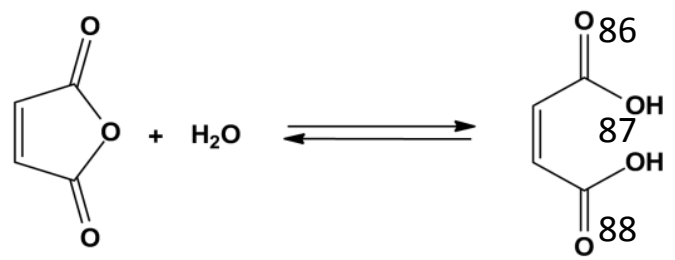

(Eq. 1)

89 In general, dicarboxylic acids can lose a water molecule and form the corresponding anhydride at temperatures $>150{ }^{\circ} \mathrm{C}$ (i.e. the reverse reaction shown in Eq.1). The specific

91 temperature at which this reaction occurs, varies by species (Koehler et al., 2004). Because

92 dicarboxylic acids are ubiquitous in the atmosphere, there is potential for anhydrides to form as 
artifacts of analysis by gas chromatography, where high temperatures are encountered (Dilorenz, 1971).

Although numerous chromatographic methods have been developed for quantification of furandiones, their ambient concentrations have yet to be quantified. Predominantly, a derivatization step has been used to reduce the reactivity of these compounds and improve the chromatographic accuracy and reproducibility (CDC, 2015; Dahlin et al., 2004; Geyer and Saunders, 1986). However, with derivatization, it becomes impossible to distinguish between anhydrides and their corresponding dicarboxylic acids that are often present in the sample matrix; consequently, reported values are the sum of acids and anhydrides. Only a few methods have discussed the direct quantification of furandiones without derivatization. Direct gas chromatography- mass spectrometry (GC-MS) methods were used to quantify furandiones in smog chambers (Forstner et al., 1997; Hamilton et al., 2005) and indoor occupational settings (Pfaffli et al., 2002). All of these methods involve using a temperature $\geq 230^{\circ} \mathrm{C}$ during sample preparation and/or analysis. At such a high temperature, the dicarboxylic acids in the sample matrix undergo interconversion to their anhydride, introducing quantification artifact.

In the present study, a gas chromatography-mass spectrometry (GC-MS) method was developed, validated, and applied to the direct quantification of furandiones in atmospheric aerosol. Target analytes included 2,5-furandione (FD), 3-methyl-2,5-furandione (MFD), dihydro2,5-furandione (DFD), dihydro-3-methyl-2,5-furandione (DMFD). Method validation included assessing positive and negative analysis artifacts and the influence of the sample matrix on quantification. Also, the current study introduces an efficient protocol for extraction and recovery of furandiones from quartz fiber filters. Our results include the first measurements of furandiones in ambient fine particulate matter $\left(\mathrm{PM}_{2.5}\right)$.

\section{Materials and methods}

\subsection{Sample collection}

$\mathrm{PM}_{2.5}$ filter samples were collected daily from September 26 to October 6, 2014 in Iowa City, IA, USA (+41.6572, - 91.5035). PM $_{2.5}$ was collected with a medium-volume URG air sampler (3000B, URG Corp.) with a cyclone (URG) operating at a flow rate of $90 \mathrm{~L} \mathrm{~min}^{-1}$. The sampler was installed on a wooden platform, and the inlet was positioned $3.5 \mathrm{~m}$ above ground 
level. Samples were collected on 90-mm quartz fiber filters (Pallflex ${ }^{\circledR}$ Tissuquartz ${ }^{\mathrm{TM}}$, Pall life science) that were pre-cleaned by baking for 18 hours at $550{ }^{\circ} \mathrm{C}$. Air flow rate was monitored before and after sampling using a rotameter (Gilmont Inst.). Samples were collected for 23 hours, and filter changing was performed at 8:00 am (CST). After sample collection, filters were transferred to Petri dishes, enveloped with prebaked aluminum foil, sealed with Teflon tape, and stored frozen at $-20{ }^{\mathrm{O}} \mathrm{C}$ until analysis. One field blank was collected for every five samples. Hourly $\mathrm{PM}_{2.5}$ mass measurements were obtained from the Iowa Department of Natural Resources (DNR) nearby air quality monitoring site (+41.6572, -91.5035$)$ located $3.2 \mathrm{~km}$ east of the filter sampling site (EPA, Accessed November 20, 2015). PM $_{2.5}$ mass data were only used for filter sampling periods when hourly measurements were available for the entire sampling period.

\subsection{Extraction.}

Prior to extraction, isotopically labeled internal standards (2,5-furandione $-\mathrm{D}_{2}$ (Aldrich) and dihydro-2,5-furandione -2,2,3,3- $\mathrm{D}_{4}$ (Aldrich)) were spiked onto the filter. Filters were extracted sequentially by ultra-sonication with three $10 \mathrm{~mL}$ portions of acetonitrile (Optima-Fisher Scientific-Fisher Chemical). The combined extracts were reduced to $1 \mathrm{~mL}$ by rotary-evaporation under the following conditions: $27^{\circ} \mathrm{C}, 120 \mathrm{rpm}$, and $200 \mathrm{mbar}$. Afterward, the reduced extracts were filtered $\left(0.25 \mu \mathrm{m}\right.$, PTFE syringe filter) and stored frozen at $-20^{\circ} \mathrm{C}$. Immediately prior to analysis, the extracts were further evaporated to a final volume of $100 \mu \mathrm{L}$ under a gentle stream of nitrogen at $27^{\circ} \mathrm{C}$. To test the efficiency of the extraction, spike recovery samples were analyzed.

\subsection{GCMS analysis.}

Furandiones were analyzed using an Agilent 7890A GC coupled with 5975C MS (Agilent Technologies). Under the optimized GC conditions, a $1 \mu \mathrm{L}$ aliquot of extract was injected to the GC inlet operating in the pulsed splitless mode at an initial pressure of 25 psi and temperature of $150{ }^{\circ} \mathrm{C}$. Helium (Praxair, 99.999\%) was used as a carrier gas at a constant flow rate of $2 \mathrm{~mL}$ $\min ^{-1}$. The injected sample was then introduced to a HP-20M (Hewlett-Packard) Carbowax column $(25 \mathrm{~m} \times 0.32 \mathrm{~mm} \times 0.3 \mu \mathrm{m})$. The stationary phase in this column is not bonded or crosslinked to the column wall, and thus temperature cannot exceed $220{ }^{\circ} \mathrm{C}$ to assure high sensitivity, repeatability, and to avoid bleeding. The GC oven temperature was held at $80{ }^{\circ} \mathrm{C}$ for 2 minutes and then ramped at a rate of $10{ }^{\circ} \mathrm{C}$ min $^{-1}$ until $220{ }^{\circ} \mathrm{C}$. A quadrupole mass spectrometer with an 
electron impact (EI) ionization source $(70 \mathrm{eV})$ was used. The MS source and MS quadrupole were maintained at $230{ }^{\circ} \mathrm{C}$ and $150{ }^{\circ} \mathrm{C}$, respectively. The GC-MS data were acquired in total ion scan mode over $m / z$ 40-550. The target molecules were identified against standards by their retention time, molecular ion peak, and major fragment ions. For quantitation purposes, analyte responses were normalized to the responses of deuterated internal standards. Specifically, FD was normalized to 2,5-furandione $-\mathrm{D}_{2}$, while MFD, DFD, and DMFD were normalized to dihydro-2,5-furandione - $\mathrm{D}_{4}$. Eight-point calibration curves were used in quantification. Instrument detection limits (Pankow and Bidleman) for the target analytes were determined as three times the standard deviation for the seven injections of standard solution at a concentration level of $0.0100 \mathrm{ng}_{\mu \mathrm{L}^{-1}}$. Instrument quantification limits (IQL) were determined as ten times this standard deviation. Analytical uncertainties were propagated from the limit of detection and 10\% of the measured value.

Setting the injection port to $150{ }^{\circ} \mathrm{C}$ will allow compounds with high-boiling points in PM samples to retain on the inlet liner, lowering analysis performance. Routine inlet liner maintenance is required to overcome this problem. Dichloromethane solvent was injected at 1:100 spilt ratio (to minimize transfer of compounds with high boiling points to the column) and at a higher inlet temperature $\left(250{ }^{\circ} \mathrm{C}\right)$, after each sample injection to clean the inlet of any such residue.

For the study of analysis artifacts, mixtures of furandiones and their corresponding hydrolysis products (dicarboxylic acids) were analyzed. First, furandiones and their corresponding dicarboxylic acids were prepared at $10 \mathrm{ng} \mu \mathrm{L}^{-1}$ each were analyzed with inlet temperatures of $150,170,190,210,230$, and $250^{\circ} \mathrm{C}$. To examine the influence of higher dicarboxylic acid-to-furandione molar ratios on quantification artifact, a $1 \mathrm{ng} \mu \mathrm{L}^{-1}$ mixture of three furandiones (FD, DFD, and MFD) was prepared and three dicarboxylic acids ((2Z)-2butenedioic acid, butanedioic acid, (2Z)-2-methyl-2-butenedioic acid) were added at molar ratios of $1,2,5$, and 10 , and then analyzed at inlet temperatures of $150{ }^{\circ} \mathrm{C}$.

\section{Results and discussion}

\subsection{GC-MS identification and separation of furandiones}


The optimized GC program provided baseline chromatographic resolution of the four target analytes within a 17 minute chromatographic runtime (Figure 1a). Retention times for each analyte, molecular ions, and major fragment ions used for compound identification are summarized in Table 1. The optimized GC method also provided adequate separation of the target analyzed in the $\mathrm{PM}_{2.5}$ sample matrix (Figure 1b). The selected ion chromatograms (m/z $42,54,56$, and 68 ) were common to many peaks in the chromatogram, reflecting the complexity of the sample and commonality of these low mass fragments. The optimized GC program provides sufficient resolution of the target analytes for the purpose of individual compound quantitation.

\subsection{Method performance}

The internal standard-normalized response ratios for the four furandione compounds were linear from 0.01-20.00 ng $\mu \mathrm{L}^{-1}$ with a correlation coefficient $\left(\mathrm{R}^{2}\right) \geq 0.998$ (Table 1). IDL ranged

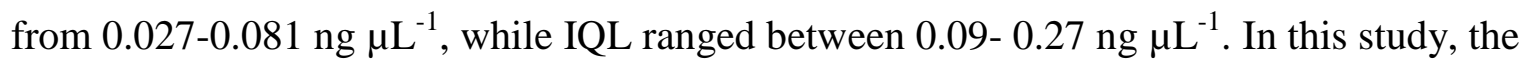
extracted filters were sampled by passing $124 \pm 0.7 \mathrm{~m}^{3}$ of air. The concentration of furandiones detected in the extracted samples was found to be continuously higher than $1 \mathrm{ng} \mu \mathrm{L}^{-1}$ for FD, DFD, and MFD, which is at least four times higher than IQL. However, ambient concentration for DMFD ranged from BDL to $1.5 \mathrm{ng} \mu \mathrm{L}^{-1}$. When comparing this method to a prior study that used HPLC along with derivatization (OSHA, 1990), the LOQ in the HPLC method was lower (0.0083 $\mathrm{ng} \mu \mathrm{L}^{-1}$ ), but did not provide distinction between furandiones and hydrolysis products.

The extraction recoveries for FD, DFD, MFD, and DMFD ranged 96.7-99.3\%, 89.9$101.1 \%, 85.1-101.4 \%, 94.7-108.2 \%$ and averaged $98.0 \pm 1.4,97.10 \pm 5.0,94.5 \pm 7.4$, and 102.8 \pm 5.9 , respectively (Table 1). All the values fall within $100 \pm 15 \%$, suggesting that the inaccuracy associated with the method and the applied extraction protocol is $<15 \%$. Also, the relative standard deviation (RSD) was used to assess the precision of this method. RSD values were $1.5 \%$ for FD, $5.0 \%$ for DFD, $7.9 \%$ for MFD, and $5.7 \%$ for DMFD. Taking into account the high volatility nature of the studied furandiones, the RSD results indicated a reliable precision of the optimized method to extract furandiones from quartz fiber filter without a significant loss of analyte. With these results, the analytical uncertainty of our measurement for FD, MFD, and DMFD was estimated to be 10\%. DFD has an increased estimated error of $19 \%$, to account for an estimated 16\% positive artifact caused by butanedioic acid as described in section 3.3. 


\subsection{Artifact during furandione analysis}

Because furandiones may form from the dehydration of dicarboxylic acids at high temperatures, the effect of GC inlet temperature on furandione measurements was investigated. The potential for artifact formation at GC inlet temperatures, ranging from $150-250{ }^{\circ} \mathrm{C}$, was first assessed using solutions with equal molar concentrations of furandiones and the corresponding dicarboxylic acids (Figure 2). At an inlet temperature of $250{ }^{\circ} \mathrm{C}$, furandione caused by the artifacts ranged from 30-50\%. The artifact formation was very consistent across 3 replicate runs, with RSDs less than 5\%. Positive artifacts were eliminated when the inlet temperature was set to $150{ }^{\circ} \mathrm{C}$ (Figure 2), which was the optimized inlet temperature. At equimolar concentrations of MFD and (2Z)-2-methyl-2-butenedioic acid, the dicarboxylic acid does not cause a measurable positive artifact in the MFD response at an inlet temperature of $150{ }^{\circ} \mathrm{C}$ as shown in Figure 2 . In comparison, Koehler et al. (2004) shows that (2Z)-2-methyl-2-butenedioic acid (a.k.a. citraconic acid) can form MFD at this injection temperature. Together, these results suggest that although some dehydration of (2Z)-2-methyl-2-butenedioic acid occurs at $150{ }^{\circ} \mathrm{C}$, its contribution to the MFD response is negligible. The smaller standard deviations in analyte responses in this study compared to those of Koehler et al. (2004) is attributed to our use of internal standards for normalization. The temperature-dependence of the positive quantification artifact shown in Figure 2 might explain the higher concentration of furandiones reported in prior studies, in which GC was used for detection (Forstner et al., 1997).

In addition to equimolar concentrations of acids to furandiones, the potential for dicarboxylic acids to interfere with furandione detection was examined at higher dicarboxylic acid-to-furandione ratios that are expected in ambient PM. Concentrations of the dicarboxylic acids ((2Z)-2-butenedioic acid, (2Z)-2-methyl-2-butenedioic acid ,butanedioic acid , and 2methylbutanedioic acid) reported in the literature vary widely by location (Ho et al., 2007), season (Pavuluri et al., 2010), time of the day (Kawamura and Yasui, 2005), and aerosol size fraction (Deshmukh et al., 2016). Since dicarboxylic acids and furandiones have not been reported together in ambient PM, we estimate the concentration of dicarboxylic acids using the dicarboxylic acid concentrations from the literature normalized to organic carbon and the average OC concentration in Iowa City reported previously (Jayarathne et al., 2016). Prior studies report OC fractions of $0.02-0.12 \%$ for (2Z)-2-butenedioic acid, $0.03-0.51 \%$ for butanedioic acid, 0.02- $0.04 \%$ for (2Z)-2-methyl-2-butenedioic acid, and $0.02-0.04 \%$ for 2- 
244

245

246

247

248

249

250

251

252

253

254

255

256

257

258

259

260

261

262

263

264

265

266

267

268

269

270

271

272

273

methylbutanedioic acid (Deshmukh et al., 2016; Ho et al., 2007). To examine the maximum potential artifact, we used the maximum dicarboxylic acid-to-OC ratios in this estimation and note that this is expected to be an over-estimation, because the reported dicarboxylic acid concentrations are expected to nclude both dicarboxylic acids and furandiones (as described in section 1). The average percent contributions of furandiones to OC mass are $0.09 \pm 0.06 \%$ for FD, $0.22 \pm 0.10 \%$ for DFD, $0.05 \pm 0.04 \%$ for MFD, and $0.03 \pm 0.02 \%$ for DMFD (Table S1).

Thus, expected molar ratios of dicarboxylic acids to their corresponding anhydrides are 1.1 for (2Z)-2-butenedioic acid, 2.0 for butanedioic acid, 0.7 for (2Z)-2-methyl-2-butenedioic acid, and 1.2 for 2-methylbutanedioic acid. At these molar ratios and an injector temperature of $150{ }^{\circ} \mathrm{C}$, no artifact is observed for FD and this measurement remains artifact-free until acid to FD molar ratio of 5 (Figure S1). Similarly, at a ratio of 0.7 for (2Z)-2-methyl-2-butenedioic acid to MFD, no positive artifact is observed. However, at a butanedioic acid to DFD ratio of 2.0, a 16\% positive artifact in DFD is observed, expectedly from the dehydration of butanedioic acid. The potential artifact for DMFD was not assessed due to a lack of dicarboxylic acid standard, but no appreciable artifact is expected for DMFD at the low molar ratio of 2-methylbutanedioic acid to-DMFD. To conclude, at atmospherically-relevant dicarboxylic acid to furandione ratios, quantification artifacts for FD and MFD are negligible, while a $16 \%$ positive artifact for DFD is observed.

\subsection{Quantification of Furandiones in ambient $\mathbf{P M}_{2.5}$}

The total daily concentrations of the four furandiones averaged $9.1 \pm 3.9 \mathrm{ng} \mathrm{m}^{-3}$ and ranged from 5.4 to $15.7 \mathrm{ng} \mathrm{m}^{-3}$ (Figure 3). DFD was the most abundant furandione detected in Iowa City. The detected ambient concentration of FD is well below the indoor threshold exposure limit $\left(1 \mathrm{mg} \mathrm{m}^{-3}\right)$ identified by the Occupational Safety and Health Administration (OSHA, 1990). $\mathrm{PM}_{2.5}$ mass concentrations on September 26 and 27 were $11.0 \pm 3.5$ and $11.7 \pm 3.0 \mu \mathrm{g} \mathrm{m}^{-3}$, respectively, such that furandiones accounted for $0.071-0.088 \%$ of $\mathrm{PM}_{2.5}$ mass on these days. The observed contribution of furandiones to $\mathrm{PM}_{2.5}$ is higher than that of other anthropogenic SOA tracers such as 2,3-dihydroxy-4-oxopentanoic acid and 2,3-dihydroxy-4-oxobutanoic acid (0.020-0.038\%), as reported in the literature (Lewandowski et al., 2007). These results indicate that the method is suitable for the routine determination of furandiones and will improve the current understanding to the contribution of anthropogenic SOA in atmospheric aerosol. 


\section{Conclusions}

275 Furandiones are among the most frequently identified products of aromatic VOC oxidation 276 in the presence of nitrogen oxides $\left(\mathrm{NO}_{\mathrm{x}}\right)$. A direct analytical method was developed that allowed

277 for the accurate measurements for the furandiones in ambient fine particulate matter, without 278 interferences from structurally-related dicarboxylic acid. The method was sufficiently sensitive 279 to quantify furandiones in low PM environments. When applied to $\mathrm{PM}_{2.5}$ samples collected in 280 Iowa City, IA, the targeted four furandiones were detected in all the samples with an average 281 concentration of $9.1 \pm 3.9 \mathrm{ng} \mathrm{m}^{-3}$. The developed method will provide a basis for further evaluate 282 the efficiency of using furandiones as a tracers for anthropogenic SOA. Consequently, this 283 method can be used to expand the current understanding for the contribution of the 284 anthropogenic SOA to the atmospheric particulate matter.

\section{Acknowledgments}

287 This material is based upon work supported by the National Science Foundation under Grant No. 288 1405014. The authors thank University of Iowa graduate student John Groenenboom for filter 289 sample collection. 


\section{References}

Bandow, H., Washida, N., Akimoto, H., 1985. Ring-cleavage reactions of aromatic-hydrocarbons studied by FTIR spectroscopy: Photooxidation of toluene and benzene in the nox-air system. Bull. Chem. Soc. Jpn. 58, 2531-2540.

CDC, 2015. NIOSH Pocket Guide to Chemical Hazards: Maleic Anhydride. , http://www.cdc.gov/niosh/npg/npgd0376.html (accessed September 14th, 2015).

Dahlin, J., Karlsson, D., Skarping, G., Dalene, M., 2004. Determination of airborne anhydrides using LCMS monitoring negative ions of di-n-butylamine derivatives. J. Environ. Monit. 6, 624-629.

Deshmukh, D.K., Kawamura, K., Deb, M.K., 2016. Dicarboxylic acids, omega-oxocarboxylic acids, alpha-dicarbonyls, WSOC, OC, EC, and inorganic ions in wintertime size-segregated aerosols from central India: Sources and formation processes. Chemosphere 161, 27-42.

Dilorenz, A.D., 1971. Quantitative analysis of maleic and citraconic anhydrides by gas chromatography. J. Chromatogr. 55, 303-\&.

Dockery, D.W., Pope, C.A., Xu, X.P., Spengler, J.D., Ware, J.H., Fay, M.E., Ferris, B.G., Speizer, F.E., 1993. An Associated Between Air Pollution and Mortality in 6 United States Cities. N. Engl. J. Med. 329, 1753-1759.

EPA, 1992. Technology Transfer Network-Air Toxics Web Site.

EPA, Accessed November 20, 2015. Air Quality System Data Mart [internet database] available via http://www.epa.gov/airdata.

Fine, P.M., Chakrabarti, B., Krudysz, M., Schauer, J.J., Sioutas, C., 2004. Diurnal variations of individual organic compound constituents of ultrafine and accumulation mode particulate matter in the Los Angeles basin. Environmental Science \& Technology 38, 1296-1304.

Foley, K.M., Roselle, S.J., Appel, K.W., Bhave, P.V., Pleim, J.E., Otte, T.L., Mathur, R., Sarwar, G., Young, J.O., Gilliam, R.C., Nolte, C.G., Kelly, J.T., Gilliland, A.B., Bash, J.O., 2010. Incremental testing of the Community Multiscale Air Quality (CMAQ) modeling system version 4.7. Geosci. Model Dev. 3, 205-226.

Forstner, H.J.L., Flagan, R.C., Seinfeld, J.H., 1997. Secondary organic aerosol from the photooxidation of aromatic hydrocarbons: Molecular composition. Environ. Sci. Technol. 31, 1345-1358.

Geyer, R., Saunders, G.A., 1986. Determination of Maleic-Anhydride in Workplace Air by ReversedPhase High-Performance Liquid-Chromatography. J. Chromatogr. 368, 456-458.

Hallquist, M., Wenger, J.C., Baltensperger, U., Rudich, Y., Simpson, D., Claeys, M., Dommen, J., Donahue, N.M., George, C., Goldstein, A.H., Hamilton, J.F., Herrmann, H., Hoffmann, T., Iinuma, Y., Jang, M., Jenkin, M.E., Jimenez, J.L., Kiendler-Scharr, A., Maenhaut, W., McFiggans, G., Mentel, T.F., Monod, A., Prevot, A.S.H., Seinfeld, J.H., Surratt, J.D., Szmigielski, R., Wildt, J., 2009. The formation, properties and impact of secondary organic aerosol: current and emerging issues. Atmos. Chem. Phys. 9, 5155-5236.

Hamilton, J.F., Lewis, A.C., Bloss, C., Wagner, V., Henderson, A.P., Golding, B.T., Wirtz, K., MartinReviejo, M., Pilling, M.J., 2003. Measurements of photo-oxidation products from the reaction of a series of alkyl-benzenes with hydroxyl radicals during EXACT using comprehensive gas chromatography. Atmos. Chem. Phys. 3, 1999-2014.

Hamilton, J.F., Webb, P.J., Lewis, A.C., Reviejo, M.M., 2005. Quantifying small molecules in secondary organic aerosol formed during the photo-oxidation of toluene with hydroxyl radicals. Atmos. Environ. 39, 7263-7275.

Henze, D.K., Seinfeld, J.H., Ng, N.L., Kroll, J.H., Fu, T.M., Jacob, D.J., Heald, C.L., 2008. Global modeling of secondary organic aerosol formation from aromatic hydrocarbons: high- vs. lowyield pathways. Atmos. Chem. Phys. 8, 2405-2420.

Ho, K.F., Cao, J.J., Lee, S.C., Kawamura, K., Zhang, R.J., Chow, J.C., Watson, J.G., 2007. Dicarboxylic acids, ketocarboxylic acids, and dicarbonyls in the urban atmosphere of China. Journal of Geophysical Research-Atmospheres 112. 
IPCC, 2007. Forster, P., Ramaswamy, V., Artaxo, P., Berntsen, T., Betts, R., Fahey, D.W., Haywood, J., Lead, J., Lowe, D.C., Myhre, G., Nganga, J., Prinn, R., Raga, G. B., Schulz, M., Van Dorland, R. Chapter 2: Changes in Atmospheric Constituents and in Radiative Forcing. Climate Change 2007: The Physical Science Basis. Contribution of Working Group I to the Fourth Assessment Report of the Intergovernmental Panel on Climate Change.

Jang, M.S., Kamens, R.M., 2001. Characterization of secondary aerosol from the photooxidation of toluene in the presence of NOx and 1-propene. Environ. Sci. Technol. 35, 3626-3639.

Jayarathne, T., Rathnayake, C.M., Stone, E.A., 2016. Local source impacts on primary and secondary aerosols in the Midwestern United States. Atmos. Environ. 130, 74-83.

Kawamura, K., Yasui, O., 2005. Diurnal changes in the distribution of dicarboxylic acids, ketocarboxylic acids and dicarbonyls in the urban Tokyo atmosphere. Atmos. Environ. 39, 1945-1960.

Kleindienst, T.E., Conver, T.S., McIver, C.D., Edney, E.O., 2004. Determination of secondary organic aerosol products from the photooxidation of toluene and their implications in ambient PM2.5. Journal of Atmospheric Chemistry 47, 79-100.

Kleindienst, T.E., Jaoui, M., Lewandowski, M., Offenberg, J.H., Lewis, C.W., Bhave, P.V., Edney, E.O., 2007. Estimates of the contributions of biogenic and anthropogenic hydrocarbons to secondary organic aerosol at a southeastern US location. Atmos. Environ. 41, 8288-8300.

Kleindienst, T.E., Smith, D.F., Li, W., Edney, E.O., Driscoll, D.J., Speer, R.E., Weathers, W.S., 1999. Secondary organic aerosol formation from the oxidation of aromatic hydrocarbons in the presence of dry submicron ammonium sulfate aerosol. Atmos. Environ. 33, 3669-3681.

Koehler, C.A., Fillo, J.D., Ries, K.A., Sanchez, J.T., De Haan, D.O., 2004. Formation of secondary organic aerosol by reactive condensation of furandiones, aldehydes, and water vapor onto inorganic aerosol seed particles. Environ. Sci. Technol. 38, 5064-5072.

Kroll, J.H., Seinfeld, J.H., 2008. Chemistry of secondary organic aerosol: Formation and evolution of low-volatility organics in the atmosphere. Atmospheric Environment 42, 3593-3624.

Lewandowski, M., Jaoui, M., Kleindienst, T.E., Offenberg, J.H., Edney, E.O., 2007. Composition of PM2.5 during the summer of 2003 in Research Triangle Park, North Carolina. Atmos. Environ. 41, 4073-4083.

NIH, Toxicology Data Network-HSDB: Succinic Anhydride, http://toxnet.nlm.nih.gov/ (accessed September 14th, 2015).

Offenberg, J.H., Lewis, C.W., Lewandowski, M., Jaoui, M., Kleindienst, T.E., Edney, E.O., 2007. Contributions of toluene and alpha-pinene to SOA formed in an irradiated toluene/alphapinene/NOx/air mixture: Comparison of results using C-14 content and SOA organic tracer methods. Environmental Science \& Technology 41, 3972-3976.

OSHA, 1990. OSHA Methods 25-Maleic Anhydride, in: Laboratory, A. (Ed.), Salt Lake City, UT.

Pankow, J.F., Bidleman, T.F., 1991. Effects of temperature, TSP and per cent nonexchangeable material in determining the gas particle partitioning of organic-compounds. Atmospheric Environment Part a-General Topics 25, 2241-2249.

Pavuluri, C.M., Kawamura, K., Swaminathan, T., 2010. Water-soluble organic carbon, dicarboxylic acids, ketoacids, and alpha-dicarbonyls in the tropical Indian aerosols. Journal of Geophysical Research-Atmospheres 115.

Pfaffli, P., Hameila, M., Kuusimaki, L., Wirmoila, R., 2002. Determination of maleic anhydride in occupational atmospheres. J. Chromatogr. A 982, 261-266.

Volkamer, R., Jimenez, J.L., San Martini, F., Dzepina, K., Zhang, Q., Salcedo, D., Molina, L.T., Worsnop, D.R., Molina, M.J., 2006. Secondary organic aerosol formation from anthropogenic air pollution: Rapid and higher than expected. Geophys. Res. Lett. 33. 


\section{Figure Captions}

387 Fig. 1. Selected ion chromatogram for a) standard solution $\left(10 \mathrm{ng} \mu \mathrm{L}^{-1}\right)$ for a mixture of the four 388 anhydrides of interest, and b) ambient $\mathrm{PM}_{2.5}$ sample from Iowa City 29 September 2014.

389 Fig. 2. The effect of inlet temperature on the normalized recovered concentration of the 390 anhydrides in a $10 \mathrm{ng} / \mu \mathrm{L}$ mixture of four furandiones and (2Z)-2-butenedioic acid, butanedioic 391 acid, and (2Z)-2-methyl-2-butenedioic acid. Setting the inlet temperature at $150{ }^{\circ} \mathrm{C}$ eliminates 392 positive analysis artifact.

393 Fig. 3. Ambient concentrations of furandiones in $\mathrm{PM}_{2.5}$ samples from Iowa City, 2014. 
394 Table 1: Summary of furandione retention times, molecular and base peaks, GCMS method performance metrics, and extraction 395 recoveries ( \pm one standard deviation, $n=4$ )

\begin{tabular}{|c|c|c|c|c|c|c|c|c|c|}
\hline Analyte & $\begin{array}{l}\text { Abbrevi } \\
\text { ation }\end{array}$ & $\begin{array}{l}\text { Retention } \\
\text { time }\end{array}$ & $\begin{array}{c}\text { Molecular } \\
\text { ion } \\
(\mathrm{m} / \mathrm{z})\end{array}$ & $\begin{array}{l}\text { Base } \\
\text { peak } \\
(\mathrm{m} / \mathrm{z})\end{array}$ & $\begin{array}{l}\text { Linear range } \\
\qquad\left(\operatorname{ng} \mu l^{-1}\right)\end{array}$ & $\mathrm{R}^{2}$ & $\begin{array}{c}\text { Instrument } \\
\text { detection } \\
\text { limit }\left(\operatorname{ng} \mu l^{-1}\right)\end{array}$ & $\begin{array}{l}\text { Instrument } \\
\text { quant. limit } \\
\left(\mathrm{ng} \mu \mathrm{l}^{-1}\right)\end{array}$ & $\begin{array}{l}\text { Extraction } \\
\text { recovery } \\
(\%)\end{array}$ \\
\hline 2,5-Furandione & FD & 7.8 & 98.0 & 54 & $0.027-20.000$ & 0.998 & 0.027 & 0.090 & $97.9 \pm 1.5$ \\
\hline $\begin{array}{l}\text { Dihydro-2,5- } \\
\text { furandione }\end{array}$ & DFD & 11.6 & 100.0 & 56 & $0.028-20.000$ & 0.999 & 0.028 & 0.093 & $97.1 \pm 4.9$ \\
\hline $\begin{array}{l}\text { 3-Methyl-2,5- } \\
\text { furandione }\end{array}$ & MFD & 7.6 & 112.0 & 68 & $0.081-20.000$ & 0.999 & 0.081 & 0.270 & $94.5 \pm 7.5$ \\
\hline $\begin{array}{l}\text { Dihydro-3-methyl-2,5- } \\
\text { furandione }\end{array}$ & DMFD & 10.0 & $114.1^{\mathrm{a}}$ & 42 & $0.067-20.000$ & 0.999 & 0.067 & 0.223 & $102.8 \pm 5.9$ \\
\hline
\end{tabular}


Figure 1

a) Chromatographic separation of furandiones

401

402

403

404

405

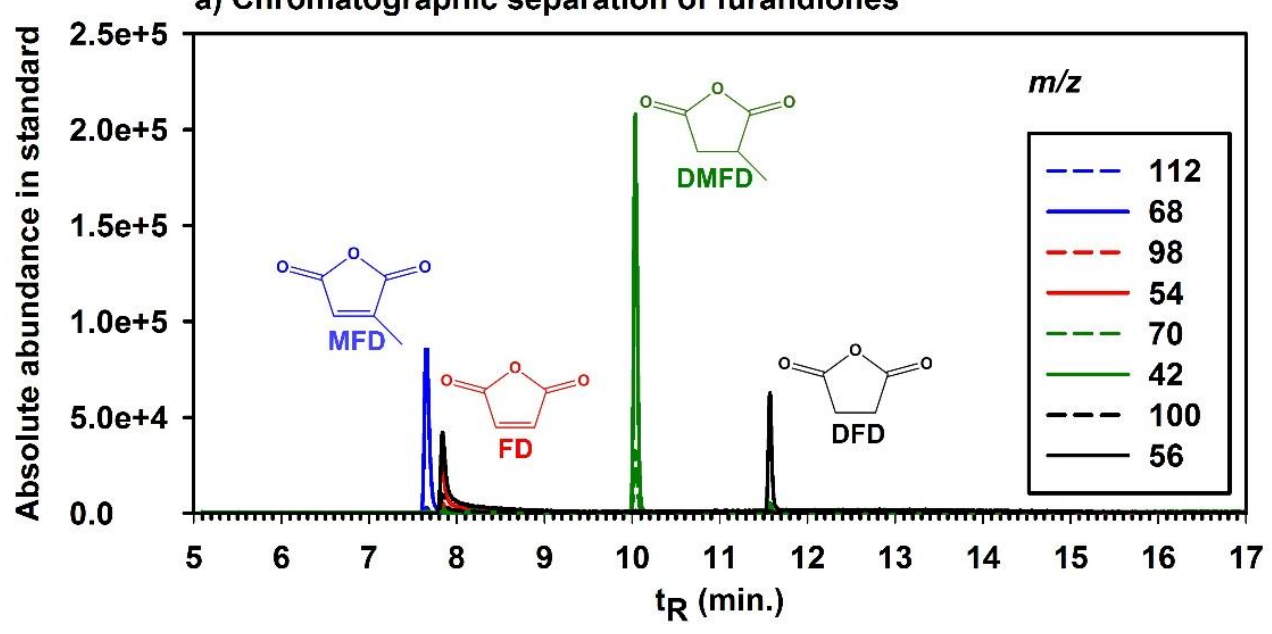

b) Extracted ion chromatograms for standard and sample

408

409

410
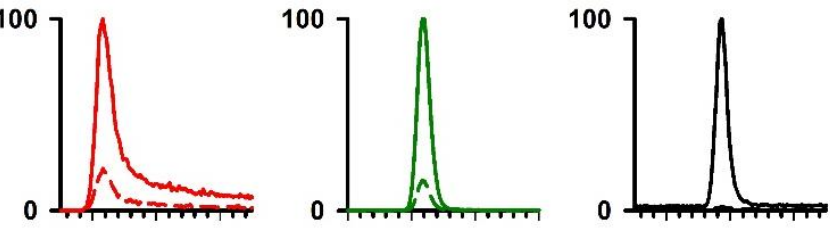

411

412
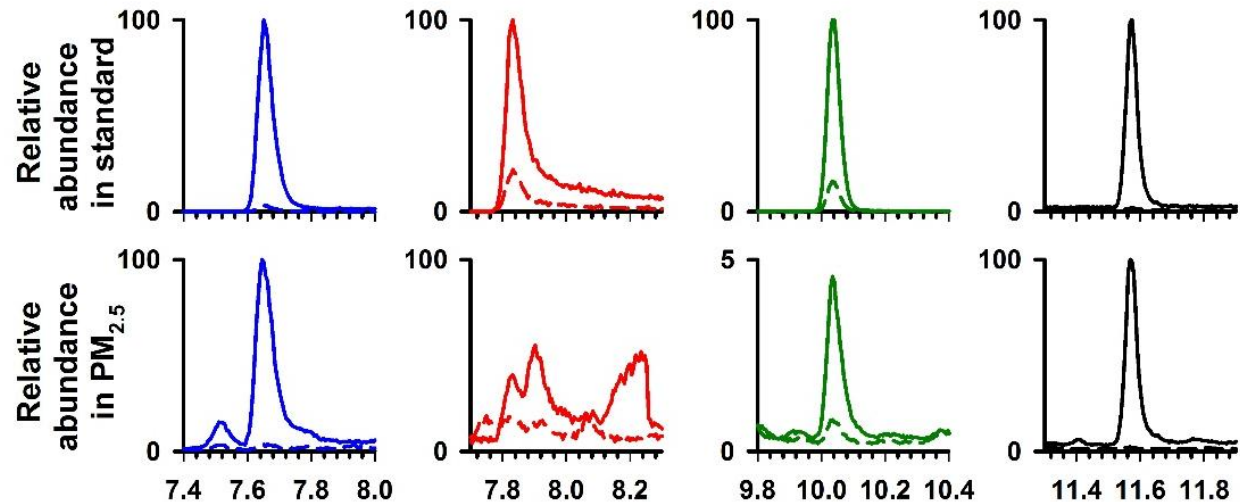

414

415
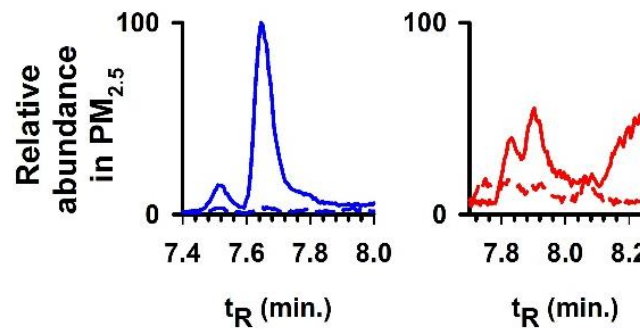

$t_{R}$ (min.)

$t_{R}$ (min.) 
Figure 2

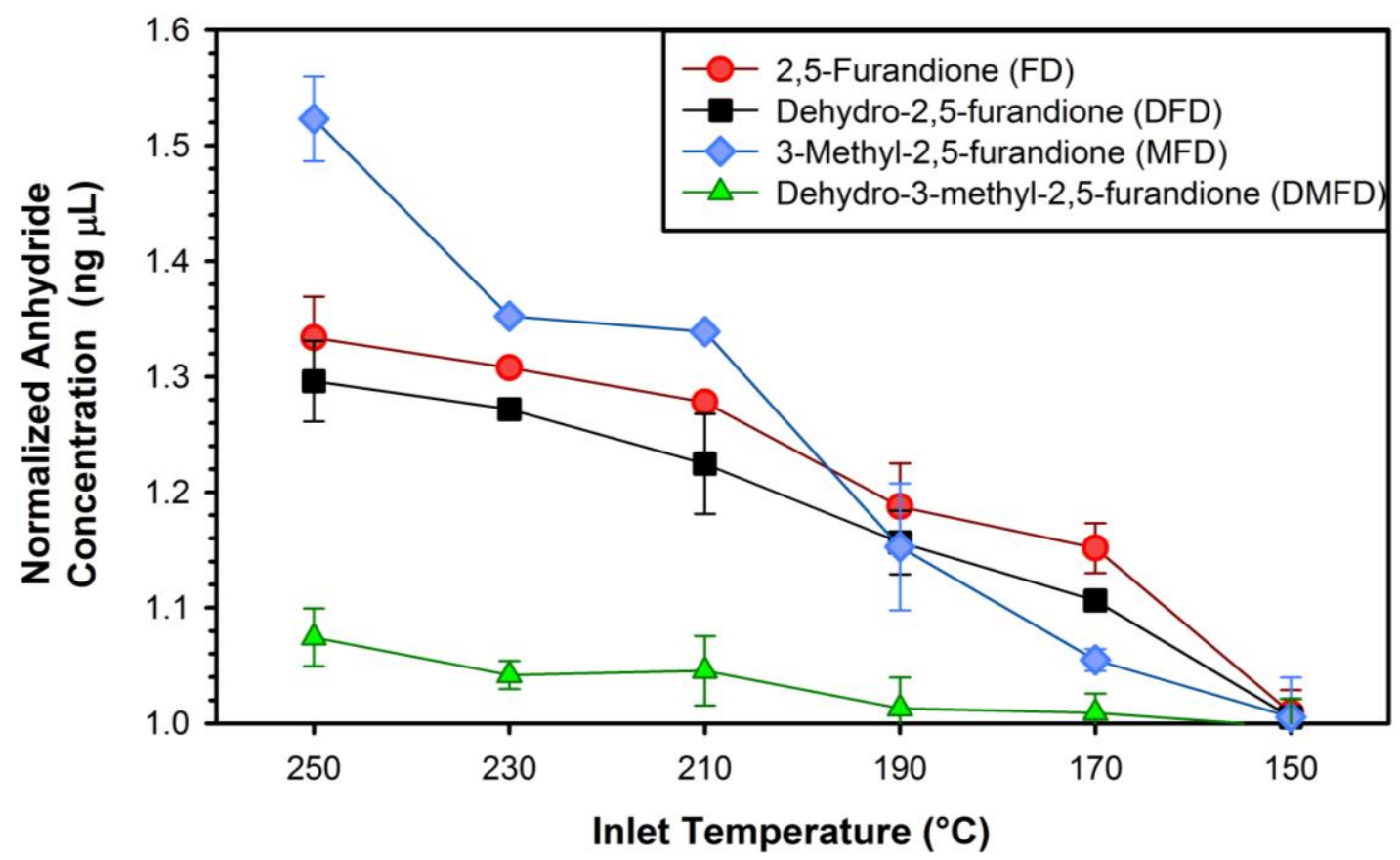

417 
Figure 3

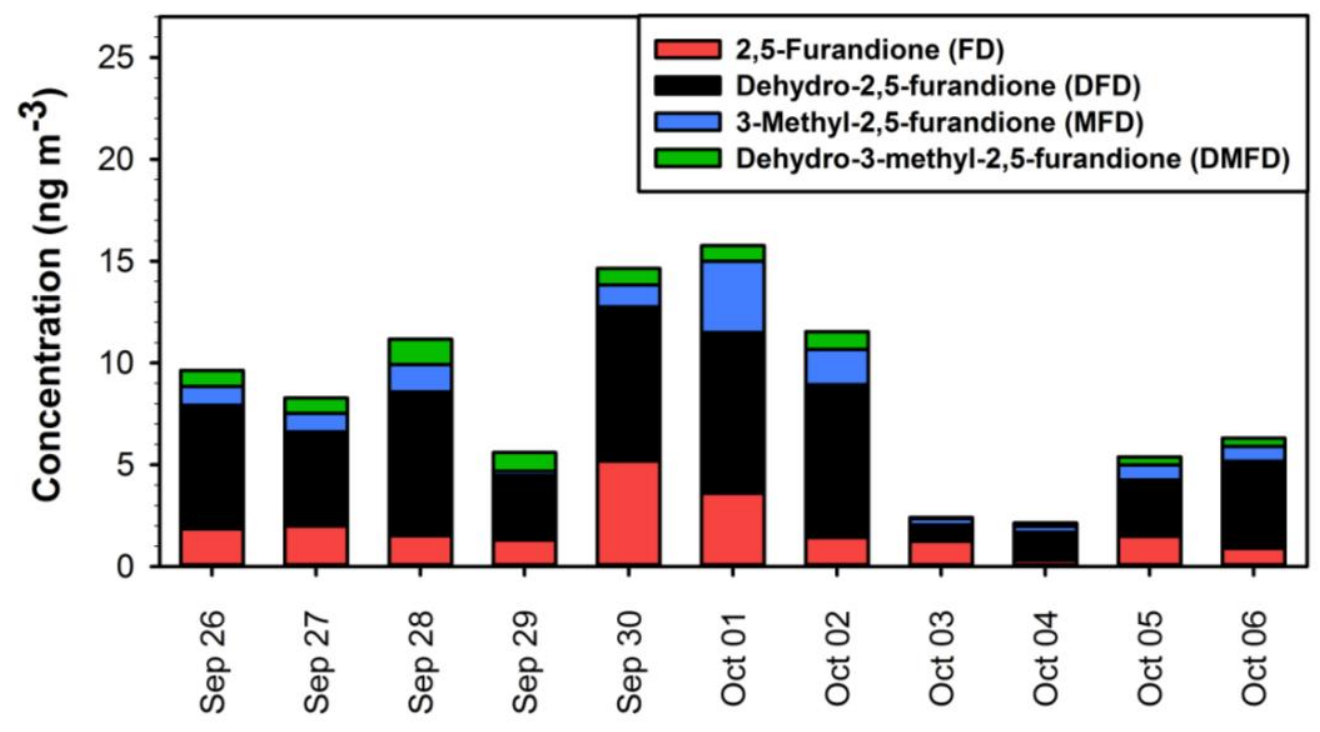

